\title{
Transdifferentiated rat pancreatic progenitor cells (AR42J-B13/H) respond to phenobarbital in a rat hepatocyte-specific manner.
}

\author{
Osborne, M. ${ }^{1}$, Haltalli, M. ${ }^{1}$, Currie, R. ${ }^{2}$, Wright, $\mathrm{J.}^{2}$ and Gooderham, N.J1*. \\ 1 Computational and Systems Medicine, Department of Surgery and Cancer, Imperial \\ College London, London SW7 2AZ, UK
} 2 Syngenta, Jealott's Hill, Bracknell, Berkshire, RG42 6EY

*Please address correspondence to:

Nigel J Gooderham

Computational and Systems Medicine,

Department of Surgery and Cancer,

Sir Alexander Fleming Building

Imperial College London,

London SW7 2AZ, UK

Email: n.gooderham@imperial.ac.uk

Tel: 02075943188 


\section{Abstract}

Phenobarbital (PB) is known to produce species-specific effects in the rat and mouse, being carcinogenic in certain mouse strains, but only in rats if treated after a DNA damaging event. PB treatment in the rat and mouse also produces disparate effects on cell signalling and miRNA expression profiles. These responses are induced by short term and prolonged PB exposure, respectively, with the latter treatments being difficult to examine mechanistically in primary hepatocytes due to rapid loss of the original hepatic phenotype and limited sustainability in culture. Here we explore the rat hepatocyte-like $\mathrm{B} 13 / \mathrm{H}$ cell line as a model for hepatic response to PB exposure in both short-term and longer duration treatments. We demonstrate that PB with Egf treatment in the B13/H cells, resulted in a significant increase in Erk activation, as determined by the ratio of phospho-Erk to total Erk, compared to Egf alone. We also show that an extended treatment with PB in the $\mathrm{B} 13 / \mathrm{H}$ cells produces a miRNA response similar to that seen in the rat in vivo, via the time-dependent induction of miR-182/96. Additionally, we confirm that B13/H cells respond to Car activators in a typical rat-specific manner. These data suggest that the $\mathrm{B} 13 / \mathrm{H}$ cells produce temporal responses to PB that are comparable to those reported in short-term primary rat hepatocyte cultures and in the longer term are similar to those in the rat in vivo. Finally, we also show that Carassociated miR-122 expression is decreased by PB treatment in B13/H cells, a PB-induced response that is common to the rat, mouse and human. We conclude that the $\mathrm{B} 13 / \mathrm{H}$ cell system produces a qualitative response comparable to the rat, which is different to the response in the mouse, and that this model could be a useful tool for exploring the functional consequences of PB-sensitive miRNA changes and resistance to PB-mediated tumours in the rat.

Keywords: B13/H cells; phenobarbital; cyp2b; miRNA; hepatocytes; constitutive androstane receptor. 
Abbreviations: B13/H, AR42J-B13/H cells; Cyp, Cytochrome P450; PB, phenobarbital; PROD, pentoxyresorufin-O-dealkylase; qRT-PCR, quantitative reverse transcription-PCR. BSA, bovine serum albumin; Egf, epidermal growth factor; Erl., erlotinib; Veh, vehicle. DMSO, dimethyl sulphoxide; TCPOBOP, 1,4-Bis[2-(3,5-dichloropyridyloxy)]benzene. 


\section{Introduction}

Phenobarbital (PB) is a model rodent drug metabolising enzyme inducer and can cause hepatic hyperplasia and neoplasia (Butler 1978; Becker 1982; Hagiwara et al. 1999). PB acts through the constitutive androstane receptor (Car/Nr1i3), and pregnane $\mathrm{x}$ receptor (Pxr/Nr1i2) to induce genes involved in drug metabolism, energy metabolism and cell proliferation (Yang and Wang 2014), such as the prototypical PB/Car marker, Cyp2b (Honkakoski et al. 1998). PB indirectly activates Car through a signalling pathway that dephosphorylates Car, causing its translocation into the nucleus (Kawamoto et al. 1999; Yoshinari et al. 2003; Kobayashi et al. 2003). PB is an hepatocarcinogen in certain strains of mice that are predisposed to liver tumours (reviewed in (Elcombe et al. 2014), and it has been demonstrated that activation of Car is essential to PB's tumour promoting abilities (Yamamoto et al. 2004; Huang et al. 2005). In the mouse, Mutoh et al., (Mutoh et al. 2013) suggest that PB-mediated indirect activation of Car is through antagonism of the Egf receptor (Egfr).

Unlike the mouse, in the rat PB only acts as a liver tumour promoter when given after a DNA damaging compound such as diethylnitrosamine (Kolaja et al. 1996). PB also appears to exhibit disparate effects on cell signalling pathways in the mouse compared to the rat. In mouse primary hepatocytes, it has been reported (Osabe and Negishi 2011) that 1 hour PB treatment was able to reduce Erk activity, which has been linked to activation of Car, in agreement with the reported inhibition of Egfr phosphorylation (Mutoh et al. 2013). However, in rat primary hepatocytes, PB with Egf treatment has been shown to increase Erk activation (Joannard et al. 2006). This opposite effect in the rat may imply a negative feedback mechanism to modulate Car activation. This suggestion is supported by the potentiation of PB-induced Cyp2b mRNA, when also treating with an inhibitor of the Erk upstream kinase, Mek1/2, compared to PB alone (Joannard et al. 2006). The reason for this species difference remains unclear. 
Furthermore, PB treatment results in species-specific effects on the rat and mouse hepatic miRNAome. MicroRNAs are regulatory noncoding RNAs that control gene expression by targeted mRNA degradation or translation inhibition (reviewed in (Carroll et al. 2013). Lempiäinen et al., (Lempiäinen et al. 2013a) demonstrated that PB $(0.05 \% \mathrm{w} / \mathrm{v}$ in drinking water) administered to $\mathrm{B} 6 \mathrm{C} 3 \mathrm{~F} 1 / \mathrm{Cr} 1$ mice significantly increased the expression of the pluripotent-associated noncoding RNA cluster, DIk1-Dio3, which the authors suggested may be linked to the promotion of PB-mediated tumours in the mouse. However, we have shown in the rat that PB induced a different set of miRNAs, including the miR-200a/b/429 and miR96/182 clusters, in a time- and dose-dependent fashion (Koufaris et al. 2012). The miR$200 \mathrm{a} / \mathrm{b} / 429$ family has been implicated in resisting cellular changes towards a neoplastic phenotype by targeting the Zeb1/2 transcription factors (Koufaris et al. 2013).

Investigating molecular mechanisms is best accomplished using a suitable in vitro based system, and cultured primary hepatocytes are the current gold standard for toxicology testing. However primary hepatocytes rapidly lose their hepatic phenotype, and so the use of alternative models such as stem-cell derived hepatocytes has become the focus of intense research ( $\mathrm{Hu}$ and $\mathrm{Li}$ 2015). In the rat, it has been proposed that the pancreatic derived progenitor cell line, AR42J-B13 (B13 cells), offers a stable, cost-effective and easy model for generating hepatocyte-like cells known as AR42J-B13/H (B13/H) (Probert et al. 2015). It was reported by Shen et al., (Shen et al. 2000) that treatment of the undifferentiated B13 cell with dexamethasone for two weeks stimulated the cell to transdifferentiate into hepatocyte-like B13/H cells. The differentiated cell population display gene expression profiles similar to primary hepatocytes and can be maintained in culture for considerably longer than primary hepatocytes without de-differentiation (Probert et al. 2013; Probert et al. 2015), making them a useful model for the proposed treatments here.

We sought to investigate if the $\mathrm{B} 13 / \mathrm{H}$ system was a suitable cell model for temporally extended study following treatment with PB and PB-like compounds. We also interrogated 
this system for its ability to reliably reproduce PB-induced rat-specific cell signalling and miRNA expression responses. 


\section{Materials and Methods}

\subsection{Cell culture}

Cell culture consumables were purchased from Life Technologies, Gibco \& Invitrogen (Paisley, UK), or Corning (NY, USA). Rat pancreatic AR42J-B13 (B13) cells were a gift from Professor Wright (Newcastle University, UK) and were cultured in GIBCO low glucose $(1 \mathrm{~g} / \mathrm{L})$ Dulbecco's Modified Eagle Medium supplemented with foetal bovine serum (FBS) (10v/v\%), L-glutamine $(233.6 \mu \mathrm{g} / \mathrm{mL})$, penicillin $(80 U$ nits $/ \mathrm{mL})$ and streptomycin $(80 \mu \mathrm{g} / \mathrm{mL})$. B13 cells were transdifferentiated into hepatocyte-like B13/H cells by treatment with dexamethasone (10nM) for 13 days (Shen et al. 2000). Unless stated otherwise, B13/H cells were cultured for 24 hours in media lacking dexamethasone prior to further chemical treatments. The duration of chemical treatment is indicated in the text and figures. In experiments using prolonged culture (post transdifferentiation), treatments and media were refreshed every 72 h.

\subsection{RNA extraction}

MirVana PARIS RNA extraction kits (Life Technologies, Paisley, UK) were used, following the manufacturer's protocol. Samples were lysed directly from cell culture plates after washing with ice cold PBS. Kit disruption buffer was used for lysis, on ice for 10 minutes, with lysate collected and subsequently denatured with $2 x$ volume of Denaturing Solution. Acid-Phenol:Choloform extraction was used, followed by sample binding to silica filters, washing and elution in DNase/RNase free water. RNA quality and quantity was measured using spectroscopy with the IMPLEN - nanophotometer (Implen, Gmbh, Munich, Germany), and stored at $-20^{\circ} \mathrm{C}$ until required.

\subsection{PCR}

Unless otherwise stated, reagents and probes were purchased from Life Technologies (Paisley, UK). 


\subsubsection{Semi-q PCR: Reverse transcription (RT)}

RNA template (500ng-1 $\mu \mathrm{g})$ was reverse transcribed with random hexamers (300ng) using the Superscript II kit and deoxynucleotide triphosphates (dNTPs) $(425 \mu \mathrm{M})$ (Sigma-Aldrich, Dorset, England), following the Superscript II kit protocol. Negative controls were included to check for gDNA contamination. A PTC-200 Peltier Thermal Cycler was used for the RT reaction (Table 1).

Table 1: Thermal cycler and cDNA amplification conditions

\begin{tabular}{|c|c|c|c|c|c|}
\hline RT/PCR & Stage 1 & Stage 2 & Stage 3 & Stage 4 & Stage 5 \\
\hline $\begin{array}{l}\text { RT } \\
\text { (miRNA) }\end{array}$ & $\begin{array}{l}16^{\circ} \mathrm{C} \\
30 \mathrm{~min}\end{array}$ & $\begin{array}{l}42^{\circ} \mathrm{C} \\
30 \mathrm{~min}\end{array}$ & $\begin{array}{l}85^{\circ} \mathrm{C} \\
5 \mathrm{~min}\end{array}$ & $4^{\circ} \mathrm{C} \infty$ & \\
\hline $\begin{array}{l}\text { RT } \\
\text { (mRNA) }\end{array}$ & $\begin{array}{l}25^{\circ} \mathrm{C} \\
10 \mathrm{~min}\end{array}$ & $\begin{array}{l}37^{\circ} \mathrm{C} \\
120 \mathrm{~min}\end{array}$ & $\begin{array}{l}85^{\circ} \mathrm{C} \\
5 \mathrm{~min}\end{array}$ & $4^{\circ} \mathrm{C} \infty$ & \\
\hline qPCR & $\begin{array}{l}95^{\circ} \mathrm{C} \\
10 \mathrm{~min}\end{array}$ & $\begin{array}{l}95^{\circ} \mathrm{C} \\
15 \mathrm{sec}\end{array}$ & $\begin{array}{l}60^{\circ} \mathrm{C} \\
60 \mathrm{sec}\end{array}$ & $\begin{array}{l}\text { Repeat } \\
2-3 \times 39\end{array}$ & $4^{\circ} \mathrm{C} \infty$ \\
\hline
\end{tabular}

\subsubsection{Semi-q PCR}

The Tfi polymerase assay was used for $\mathrm{CDNA}(2 \mu \mathrm{L})$ amplification, following the manufacturer's instructions. Custom made primers (200nM) were used for cDNA amplification, with details shown in

Table 2 and 
Table 3. Amplicons were resolved by electrophoresis in an agarose gel (2\%) (Sigma-Aldrich,

Table 2: Semi-q PCR primer details

\begin{tabular}{|c|c|c|}
\hline \multicolumn{3}{|c|}{ mRNA semi-qPCR primers (Life Technologies) } \\
\hline Primer & Sequence (5'-3') & $\begin{array}{l}\text { Amplicon size } \\
\text { (bp) }\end{array}$ \\
\hline Gapdh Fwd & GGACCAGGTTGTCTCCTGTG & \multirow[t]{2}{*}{322} \\
\hline Gapdh Rev & GGCCCCTCCTGTTGTTATGG & \\
\hline Albumin Fwd & GCTGAGGCCAAGGATGTCTT & \multirow[t]{2}{*}{470} \\
\hline Albumin Rev & CACTTGGTGACCTTCTCGCT & \\
\hline $\begin{array}{l}\text { Amylase } 2 a 3 \\
\text { Fwd }\end{array}$ & TGGTTCTCCCAAGGAAGCAG & \multirow[t]{2}{*}{834} \\
\hline $\begin{array}{l}\text { Amylase } 2 a 3 \\
\text { Rev }\end{array}$ & CTCTTACAACTTTGAGTCGGCAT & \\
\hline
\end{tabular}

Table 3: Semi-q PCR amplification conditions

\begin{tabular}{|l|l|l|l|l|l|l|l|}
\hline PCR & Stage 1 & Stage 2 & Stage 3 & Stage 4 & Stage 5 & Stage 6 & Stage 7 \\
\hline Gapdh & $94^{\circ} \mathrm{C}$ & $94^{\circ} \mathrm{C}$ & $59^{\circ} \mathrm{C}$ & $72^{\circ} \mathrm{C}$ & Repeat \\
& $2 \mathrm{~min}$ & $30 \mathrm{sec}$ & $30 \mathrm{sec}$ & $30 \mathrm{sec}$ & $\begin{array}{l}72^{\circ} \mathrm{C} \\
2-4 \times 29\end{array}$ & $4^{\circ} \mathrm{C} \infty$ \\
& $94^{\circ} \mathrm{C}$ & $94^{\circ} \mathrm{C}$ & $60^{\circ} \mathrm{C}$ & $72^{\circ} \mathrm{C}$ & Repeat & $72^{\circ} \mathrm{C}$ & $4^{\circ} \mathrm{C} \infty$ \\
& $2 \mathrm{~min}$ & $30 \mathrm{sec}$ & $30 \mathrm{sec}$ & $30 \mathrm{sec}$ & $2-4 \times 29$ & $10 \mathrm{~min}$ & \\
\hline Albumin & $94^{\circ} \mathrm{C}$ & $94^{\circ} \mathrm{C}$ & $59^{\circ} \mathrm{C}$ & $72^{\circ} \mathrm{C}$ & Repeat & $72^{\circ} \mathrm{C}$ & $4^{\circ} \mathrm{C} \infty$ \\
& $2 \mathrm{~min}$ & $30 \mathrm{sec}$ & $30 \mathrm{sec}$ & $60 \mathrm{sec}$ & $2-4 \times 29$ & $10 \mathrm{~min}$ & \\
\hline
\end{tabular}




\subsubsection{MiRNA RT}

RNA template (5ng) was reverse transcribed using the TaqMan MicroRNA Reverse Transcription assay and miRNA-specific RT primers following the TaqMan MicroRNA Reverse Transcription assay protocol. RT reaction was performed on a thermal cycler using conditions described in Table 1.

\subsubsection{MiRNA PCR}

MiRNA cDNA $(0.67 \mu \mathrm{L})$ amplification was performed using TaqMan Fast Universal PCR Master Mix, No AmpErase UNG following the manufacturer's instructions. Each sample was run in technical triplicates. A 7500 Fast Real-Time PCR System on the 96-well fast block setting was used for cDNA amplification (Table 1). Gene expression analysis was performed using the comparative Ct method $\left(2^{-\Delta C t}\right)$ (Schmittgen and Livak 2008), relative to the internal control gene, U6.

\subsection{Pentoxyresorufin-O-dealkylase (PROD) assay}

Unless stated otherwise, assay reagents were purchased from Sigma-Aldrich (Dorset, UK). The PROD assay was used as an indicator of Cyp2b activity in the B13/H cells. (Burke et al. 1994; Langouët et al. 1997). Cyp induction was stimulated in transdifferentiated B13/H cells by PB, clotrimazole, or 1,4-Bis[2-(3,5-dichloropyridyloxy)]benzene (TCPOBOP) treatment for up to 9 days.

The PROD assay (Burke and Mayer 1974) was performed using serum-free media, and started by the addition of pentoxyresorufin $(6 \mu \mathrm{M})$. Positive controls were included (S9 fraction $(40 \mu \mathrm{g}$ protein)) using a buffer of Tris $\mathrm{HCl}(100 \mathrm{mM})$, nicotinamide adenine dinucleotide phosphate (NADPH) $(500 \mu \mathrm{M})$, glucose-6-phosphate $(10 \mathrm{mM})$, magnesium chloride $\left(\mathrm{MgCl}_{2}\right)$ (2mM) and glucose-6-phosphate-dehydrogenase (3 units). Resorufin production was measured by fluorescence change using excitation ( $\lambda 565 \mathrm{~nm})$ and emission ( $\lambda 590 \mathrm{~nm})$ wavelengths on a Synergy $\mathrm{H} 1$ Hybrid plate reader and data analysed on Gen5 
Data Analysis Software (BioTek, Swindon, UK). Fluorescence was recorded at 10 minute intervals over 2 hours, to determine the rate of resorufin production (pmol per minute per mg of total protein). To determine total protein, samples were lysed for 10 minutes on ice using RIPA buffer (Sigma Aldrich, Dorset, UK), centrifuged at 10,000g and the protein supernatant was collected. Total protein was quantified using the Bicinchoninic acid assay (Pierce, ThermoScientific, IL, USA).

\subsection{Erk and Akt activity}

After 13 days transdifferentiation, $\mathrm{B} 13 / \mathrm{H}$ cells were placed in dexamethasone-free, $5 \%$ heat inactivated dextran coated charcoal (HI-DCC) stripped FBS supplemented media for a further 72 hours before treating with rat epidermal growth factor (Egf, Sigma-Aldrich, Dorset, UK). Pre-treatments were performed with the EGFR inhibitor, erlotinib (Cayman Chemical, MI, USA) or phenobarbital-sodium (PB) (BDH Chemicals Ltd, UK) for 30 minutes prior to the addition of Egf. Protein was harvested by cell lysis using RIPA buffer (Sigma-Aldrich, Dorset, UK) on ice for at least 10 minutes. Supernatant was collected through centrifugation at $10,000 \mathrm{~g}$ and protein was quantified using the Bicinchoninic acid (BCA) assay. Erk and Akt activity were determined by immunoblot.

\subsection{Immunoblots}

Chemicals were purchased from Sigma-Aldrich (Dorset, UK), unless otherwise stated. Samples were harvested directly from cell culture plates on ice for 10 minutes; protein was preserved by the addition of protease and phosphatase (cocktail 2 and 3 ) inhibitors (diluted 1:100 in RIPA buffer). Protein supernatant was collected by centrifugation $(10,000 \mathrm{~g})$, and quantified by the BCA assay.

Samples $(20 \mu \mathrm{g} / \mathrm{sample})$ containing $\beta$-mercaptoethanol (1:20) were resolved by gel electrophoresis in a $10 \%$ acrylamide gel: containing Tris $(500 \mathrm{mM})$, sodium dodecyl sulphate (SDS) (3.4mM), ammonium persulphate $(2.7 \mathrm{mM})$ and tetramethylethylenediamine $(10.3 \mathrm{mM})$. Protran nitrocellulose membranes $(0.45 \mu \mathrm{m}$ pore) (Bio-Rad, Hertfordshire, UK) were used to 
transfer the protein via wet transfer. Blocking buffer $(5 \%$ skimmed milk in PBS- $0.1 \%$ Tween20) was used to block membranes and for antibody dilutions. Primary antibodies used were: mouse $\alpha$-Gapdh (1:1,000 dilution, Abcam, Cambridge, UK), rabbit $\alpha$-Erk and rabbit $\alpha-$ Akt (1:200, Santa Cruz, TX, USA) and rabbit $\alpha$-pAkt (Ser 473) (1:350, Santa Cruz, TX, USA) and mouse $\alpha$-pErk (human tyr 204) (1:200, Santa Cruz, TX, USA). Secondary antibodies used were a-biotin-HRP $(1: 1,000$, Cell signalling, MA, USA), to detect the biotin-labelled protein ladder, goat $\alpha$-mouse-HRP $(1: 10,000$, Abcam $)$ and goat $\alpha$-rabbit-HRP $(1: 5,000$, Abcam, Cambridge, UK). The horseradish peroxidase (HRP) reaction was initiated by the addition of Luminata Forte (Millipore, MA, USA) and detected on a Gel Doc XR+ System (Kodak, NY, USA).

\subsection{Statistics}

Data are represented as mean \pm standard error of the mean (SEM). Statistical analysis was performed using the Student's $t$ tests, or one way analysis of variance (ANOVA) with Dunnett's post test. 


\section{Results}

$\mathrm{B} 13 / \mathrm{H}$ cells were successfully transdifferentiated by 2 weeks dexamethasone treatment $(10 \mathrm{nM})$ to generate an hepatocyte-like phenotype as determined by gain of albumin expression, Cyp2b activity and an hepatocyte-like morphology (Figure 1 A-C), consistent with previous reports (Shen et al. 2000; Marek et al. 2003).

\subsection{Phenobarbital treatment}

The transdifferentiated rat $\mathrm{B} 13 / \mathrm{H}$ cell system has been reported to express a range of constitutive and inducible drug metabolising enzymes, such as the Cyp enzymes (Probert et al. 2014). Therefore the hepatocyte-like $B 13 / \mathrm{H}$ cells were subsequently treated with $\mathrm{PB}$ $(2 \mathrm{mM})$ for up to 9 days, with the treatment and media replenished every $72 \mathrm{~h}$. Analysis of the treated cells demonstrated significant increases in Cyp2b1 mRNA (Figure 2A) and Cyp2b activity across the 9 days (Figure 2B). This supported the hepatocyte-like nature of the transdifferentiated $B 13 / H$ cells and their responsiveness to $P B$ and suggests the $B 13 / H$ system appears to be a useful in vitro rat hepatic model for studying PB exposure.

\subsubsection{B13/H cell signalling}

Osabe and Negishi (Osabe and Negishi 2011) demonstrated that acute PB treatment (2mM) reduced Erk activity in mouse primary hepatocytes, while Joannard et al., (Joannard et al. 2006) reported that similar PB treatment $(3 \& 5 \mathrm{mM})$ increased Erk activation in rat primary hepatocytes. We therefore examined the effect of PB on Egf signalling and Erk activation to establish if the $\mathrm{B} 13 / \mathrm{H}$ cells responded to acute $\mathrm{PB}$ treatment similar to the rat primary hepatocyte. B13/H cells were treated with Egf $(5 \mathrm{ng} / \mathrm{mL})$ for 60 minutes, which significantly increased Erk activity, as determined by the ratio of phospho-Erk to total Erk (Figure 3 A \& B). Pre-treating B13/H cells with the EGFR inhibitor erlotinib $(10 \mu \mathrm{M})$ for 30 minutes prior to the addition Egf ablated the Erk response (Figure 3 A \& C). However, pre-treating B13/H cells with PB $(5 \mathrm{mM})$ for 30 minutes before treating with Egf $(20 \mathrm{ng} / \mathrm{mL})$ resulted in potentiating Erk activity, compared to Egf alone (Figure 3 A \& C). Treatment with a lower 


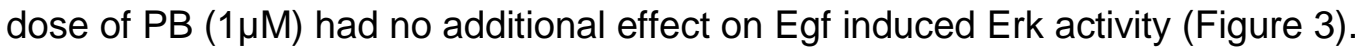
Interestingly, PB treatment alone was not able to induce Erk phosphorylation (Figure 3 A \& B), suggesting that the PB-mediated increase in pathway signalling is dependent on Egf. Similar responses were noted for Akt activity (Figure 3 D). Importantly, substituting with $\mathrm{Hgf}$ instead of Egf failed to induce a statistical significantly different response compared to $\mathrm{Hgf}$ alone (Figure 4).

Taken together these data suggest that $\mathrm{B} 13 / \mathrm{H}$ cells behave in a similar manner to rat primary hepatocytes in response to PB with Egf, with increased Erk activation, as reported by Joannard et al., (Joannard et al. 2006). This is in contrast to data reported with mouse primary hepatocytes, which show decreased Erk phosphorylation with no effect on Akt activation with PB treatment (Osabe and Negishi 2011). These data suggest that B13/H cells respond to PB and Egf treatment in a similar manner to rat primary hepatocytes, and that this is different to the response in mouse hepatocytes.

\subsubsection{B13/H cell miRNA expression}

We have previously shown that PB treatment of rats leads to altered regulation of the hepatic miRNAome (Koufaris et al. 2013). This response was both dose- and timedependent and occurred chronically rather than acutely. To further interrogate the B13/H cell model responses to $\mathrm{PB}$, we examined the miRNA expression in B13/H cells following extended treatment using a low dose $(100 \mu \mathrm{M})$ and high dose $(2 \mathrm{mM})$ PB. We chose 3 and 9 days PB treatment, as these time points reflect PB-induced miRNA expression changes seen in vivo in male Fisher rats (Koufaris et al. 2013). MiR-182 and its cluster partner miR96 are both reported to be progressively induced by PB treatment in vivo in the rat (Koufaris et al. 2012; Koufaris et al. 2013); similar changes are not seen in the mouse (Lempiäinen et al. 2013b). As previously described, B13/H cells treated with PB (2mM) for up to 9 days showed a significant increase in Cyp2b enzyme activity compared to control (Figure 2 B). Analysis of miR-96 and miR-182 expression demonstrated that 3 days PB treatment did not 
significantly increase the expression of either miRNA, while 9 days treatment at the $2 \mathrm{mM}$ dose significantly increased miR-182 and miR-96 expression compared to control (Figure 5 A and B). These data demonstrate that PB treatment of B13/H cells resulted in a dosedependent and temporal expression pattern of miR-182 and miR-96, not dissimilar to that reported in vivo (Koufaris et al. 2013).

\subsection{Clotrimazole treatment}

To explore this temporal expression further we also treated $\mathrm{B} 13 / \mathrm{H}$ cells with clotrimazole, which is a direct Car activator in the rat (Omiecinski et al. 2011). Following the same treatment scheme as described above for $\mathrm{PB}$, we demonstrated that clotrimazole $(10 \mu \mathrm{M})$ was able to significantly maintain induced Cyp enzyme activity for up to 9 days of treatment, compared to control (Figure 6 A). Interestingly, clotrimazole treatment also affected miRNA expression, but the temporal profile differed from that of PB treatment. Clotrimazole significantly induced miR-96 at 3 days treatment, but not at 9 days (Figure 6 B). This is consistent with, but independent of, the rapid induction of Cyp2b enzyme activity seen after 1 day clotrimazole treatment.

\subsection{TCPOBOP treatment}

To confirm a species-specific response, we then went on to treat the B13/H cells with the mouse-specific Car activator, 1,4-bis[2-(3,5-dichloropyridyloxy)]benzene (TCPOBOP). With TCPOBOP $(1.5 \mu \mathrm{M})$ we were unable to induce Cyp2b enzyme activity or alter miR-182 or miR-96 expression (Figure 7) over an extended treatment regimen. This suggests that the $\mathrm{B} 13 / \mathrm{H}$ cells respond to rat Car activators to induce Cyp2b enzyme activity and alter miRNA expression, but not to the mouse Car activator, TCPOBOP.

\section{4. miR-122 expression}

Finally, it has been reported that early stages of Car activation in the mouse and human is mediated by suppression of miR-122 and subsequent AMPK activation (Shizu et al. 2012; 
Kazantseva et al. 2015). We therefore analysed the expression of miR-122 levels in $B 13 / H$ cells following PB treatment for 24 hours, to determine if this Car response was also relevant to the rat. Consistent with the response in both mouse and human (Shizu et al. 2012; Kazantseva et al. 2015), 24 hours PB treatment (4mM) significantly suppressed miR-122 expression levels (Figure 8). This suggests that PB-mediated suppression of miR-122 expression appears to be a common event in the rat, mouse and human. 


\section{Discussion}

The data presented here suggests that the rat B13/H cells respond to PB in a similar manner to the rat hepatic response reported both in primary cells and in vivo. This was demonstrated independently through PB induced Cyp2b1 mRNA and Cyp2b activity, increased Erk activation with PB treatment in combination with Egf compared to Egf alone, as well as in miRNA expression profile following PB exposure.

We chose to focus on Erk phosphorylation as a downstream marker of growth factor pathway activation, with regard to Erk's reported role in modulating Car activity in mouse primary hepatocytes (Osabe and Negishi 2011), and Erk being PB-responsive in the rat in vivo (Joannard et al. 2006). We show that PB-mediated potentiation of Erk signalling appears to be specific to Egf as we could not demonstrate the same response with Hgf (Figure 4). In primary rat hepatocytes, Egf has been reported to inhibit PB-induced Cyp2b1/2 mRNA, while Hgf did not (Kawamura et al. 1999). However, in mouse primary hepatocytes both Egf and Hgf appear to be inhibitory to the PB response (Koike et al. 2007). It would be interesting to interrogate this system further and establish the effect of growth factors on Cyp2b1/2 expression in this cell line. The reason for the disparity in Egf and Hgf signalling between the mouse and rat is currently unknown.

In primary human hepatocytes, PB $(500 \mu \mathrm{M})$ increased CYP2B6 mRNA expression, whereas in the presence of EGF (75ng/mL), CYP2B6 mRNA expression was reduced compared to PB alone (Bachleda et al. 2009). This could indicate that in human primary hepatocytes EGF is acting as a negative regulator of PB-mediated gene expression, which is similar to reports in primary hepatocytes in the rat (Kawamura et al. 1999) and mouse (Koike et al. 2007). Future work could explore the role of ERK activation in primary human hepatocytes with PB and EGF treatment, and further interrogate the role this kinase plays in PB-mediated gene expression. The implications of data such as this might help to ascertain the merits of each 
model, mouse or rat, and how the model compares to the response to PB and PB-like compounds in human hepatocytes.

The expression of miR-182 and miR-96 were analysed in $\mathrm{B} 13 / \mathrm{H}$ cells to enable comparisons to the recently published in vivo data reported by Koufaris et al., (Koufaris et al. 2013). We report that PB induced the expression of miR-182 and miR-96 in a time-dependent manner in $\mathrm{B} 13 / \mathrm{H}$ cells, which is comparable to data reported in the rat in vivo (Koufaris et al. 2013). The PB-mediated induction of these miRNAs are specific to the rat, as they are not shown to be up-regulated in the mouse following PB treatment (Lempiäinen et al. 2013b). We go on to confirm that the $\mathrm{B} 13 / \mathrm{H}$ cells behave in a rat hepatic-specific manner, by demonstrating that the activity of the PB marker, Cyp2b, and the expression of the PB-sensitive miRNAs, miR182/96, are not affected by the mouse Car activator, TCPOBOP, under the conditions used here. The functions of these miRNAs in the rat may be to preserve hepatic homeostasis as indicated by their inhibition of the Zeb1/2 transcription factors, which are important in epithelial-mesenchymal transition and cancer development ( $\mathrm{Li}$ et al. 2013; Koufaris et al. 2013). Interestingly however, we do show that PB suppresses miR-122 expression in the $\mathrm{B} 13 / \mathrm{H}$ cells, which is also reported in the mouse in vivo, and human in vitro, and is thought to be important in the early stages of Car activation by PB (Shizu et al. 2012; Kazantseva et al. 2015), and was the reason for our interrogation of this miRNA. Expression of AMPK is reported to be increased through relief of miR122 inhibition and this in turn is potentially a result of Car-mediated Hnf-4 $\alpha$ suppression (Kazantseva et al. 2015). Thus in this respect, the miR122 response in the $\mathrm{B} 13 / \mathrm{H}$ cell line is consistent with that noted in other species and differentiates this response from the species-specific responses noted for miR96/182 and miR200 family clusters.

These data suggest that the $\mathrm{B} 13 / \mathrm{H}$ cells respond to PB in a rat-specific manner, akin to that reported in primary rat hepatocytes, yet also demonstrate common molecular changes (albumin expression and miR122 responses) seen in the rat, mouse and human. The B13/H cells offer a distinct advantage over primary cells in that they appear to maintain a functional 
hepatocyte-like and phenobarbital-responsive phenotype for more than 48-72 hours, and as such allow for more complex and prolonged chemical treatments. PB treatment in the B13/H cells produces a qualitative response comparable to that observed in the rat liver, which is different to the mouse hepatic response. Further in vitro analysis of the signalling and miRNA changes discussed here offer the opportunity to mechanistically understand in vivo data. We propose that the $\mathrm{B} 13 / \mathrm{H}$ cell system could provide a useful model for exploring the functional consequences of the PB-sensitive miRNA changes and potentially mechanisms involved in the resistance to PB-mediated tumours seen in the rat.

\section{Acknowledgements}

This work was supported by the BBSRC (Grant reference BB/J500811) and Syngenta Ltd, UK. 


\section{References}

Bachleda P, Vrzal R, Dvořák Z (2009) Activation of MAPKs influences the expression of drug-metabolizing enzymes in primary human hepatocytes. Gen Physiol Biophys 28:316-320. doi: $10.4149 / \mathrm{gpb}$

Becker FF (1982) Morphological classification of mouse liver tumors based on biological characteristics. Cancer Res 42:3918-3923.

Burke DM, Mayer RT (1974) Ethoxyresorufin : Microsomal Preferentially Direct Which Assay Is of O-Dealkylation By 3-Methylcholanthrene. Drug Metab Dispos 2:583-588.

Burke M, Thompson S, Weaver R, et al (1994) Cytochrome P450 specificities of alkoxyresorufin O-dealkylation in human and rat liver. Biochem Pharmacol 48:923-36.

Butler WH (1978) Long-term effects of phenobarbitone-Na on male Fischer rats. Br J Cancer $37: 418-423$.

Carroll AP, Tooney P a, Cairns MJ (2013) Context-specific microRNA function in developmental complexity. J Mol Cell Biol 5:73-84. doi: 10.1093/jmcb/mjt004

Elcombe CR, Peffer RC, Wolf DC, et al (2014) Mode of action and human relevance analysis for nuclear receptor-mediated liver toxicity: A case study with phenobarbital as a model constitutive androstane receptor (CAR) activator. Crit Rev Toxicol 44:64-82. doi: 10.3109/10408444.2013.835786

Hagiwara a, Miyata E, Tamano S, et al (1999) Non-carcinogenicity, but dose-related increase in preneoplastic hepatocellular lesions, in a two-year feeding study of phenobarbital sodium in male F344 rats. Food Chem Toxicol 37:869-79.

Honkakoski P, Zelko I, Sueyoshi T, Negishi M (1998) The nuclear orphan receptor CARretinoid $X$ receptor heterodimer activates the phenobarbital-responsive enhancer module of the CYP2B gene. Mol Cell Biol 18:5652-5658.

Hu C, Li L (2015) In vitro culture of isolated primary hepatocytes and stem cell-derived hepatocyte-like cells for liver regeneration. Protein Cell. doi: 10.1007/s13238-015-01802

Huang W, Zhang J, Washington M, et al (2005) Xenobiotic stress induces hepatomegaly and liver tumors via the nuclear receptor constitutive androstane receptor. Mol Endocrinol 19:1646-53. doi: 10.1210/me.2004-0520

Joannard F, Rissel M, Gilot D, et al (2006) Role for mitogen-activated protein kinases in phenobarbital-induced expression of cytochrome P450 2B in primary cultures of rat hepatocytes. Toxicol Lett 161:61-72. doi: 10.1016/j.toxlet.2005.08.006

Kawamoto T, Sueyoshi T, Zelko I, et al (1999) Phenobarbital-responsive nuclear translocation of the receptor CAR in induction of the CYP2B gene. Mol Cell Biol 19:6318-6322.

Kawamura a, Yoshida Y, Kimura N, et al (1999) Phosphorylation/Dephosphorylation steps are crucial for the induction of CYP2B1 and CYP2B2 gene expression by phenobarbital. Biochem Biophys Res Commun 264:530-536. doi: 10.1006/bbrc.1999.1544

Kazantseva Y a., Yarushkin A a., Mostovich L a., et al (2015) Xenosensor CAR mediates down-regulation of miR-122 and up-regulation of miR-122 targets in the liver. Toxicol Appl Pharmacol 288:26-32. doi: 10.1016/j.taap.2015.07.004

Kobayashi K, Sueyoshi T, Inoue K, et al (2003) Cytoplasmic accumulation of the nuclear receptor CAR by a tetratricopeptide repeat protein in HepG2 cells. Mol Pharmacol 64:1069-75. doi: 10.1124/mol.64.5.1069

Koike C, Moore R, Negishi M (2007) Extracellular signal-regulated kinase is an endogenous signal retaining the nuclear constitutive active/androstane receptor (CAR) in the cytoplasm of mouse primary hepatocytes. Mol Pharmacol 71:1217-1221. doi: $10.1124 / \mathrm{mol} .107 .034538$

Kolaja KL, Stevenson DE, Walborg EF, Klaunig JE (1996) Dose dependence of phenobarbital promotion of preneoplastic hepatic lesions in F344 rats and B6C3F1 mice: effects on DNA synthesis and apoptosis. Carcinogenesis 17:947-54. 
Koufaris C, Wright J, Currie R a, Gooderham NJ (2012) Hepatic microRNA profiles offer predictive and mechanistic insights after exposure to genotoxic and epigenetic hepatocarcinogens. Toxicol Sci 128:532-43. doi: 10.1093/toxsci/kfs 170

Koufaris C, Wright J, Osborne M, et al (2013) Time and dose-dependent effects of phenobarbital on the rat liver miRNAome. Toxicology 314:247-53. doi: 10.1016/j.tox.2013.10.004

Langouët S, Mahéo K, Berthou F, et al (1997) Effects of administration of the chemoprotective agent oltipraz on CYP1A and CYP2B in rat liver and rat hepatocytes in culture. Carcinogenesis 18:1343-1349. doi: 10.1093/carcin/18.7.1343

Lempiäinen $\mathrm{H}$, Couttet $\mathrm{P}$, Bolognani $\mathrm{F}$, et al (2013a) Identification of Dlk1-Dio3 imprinted gene cluster noncoding RNAs as novel candidate biomarkers for liver tumor promotion. Toxicol Sci 131:375-386. doi: 10.1093/toxsci/kfs303

Lempiäinen $\mathrm{H}$, Couttet $\mathrm{P}$, Bolognani $\mathrm{F}$, et al (2013b) Identification of Dlk1-Dio3 imprinted gene cluster noncoding RNAs as novel candidate biomarkers for liver tumor promotion. Toxicol Sci 131:375-86. doi: 10.1093/toxsci/kfs303

Li XL, Hara T, Choi Y, et al (2013) A p21-ZEB1 Complex Inhibits Epithelial-Mesenchymal Transition through the MicroRNA 183-96-182 Cluster. Mol Cell Biol 34:533-550. doi: 10.1128/MCB.01043-13

Marek CJ, Cameron G a, Elrick LJ, et al (2003) Generation of hepatocytes expressing functional cytochromes P450 from a pancreatic progenitor cell line in vitro. Biochem $\mathrm{J}$ 370:763-9. doi: 10.1042/BJ20021545

Mutoh S, Sobhany M, Moore R, et al (2013) Phenobarbital indirectly activates the constitutive active androstane receptor (CAR) by inhibition of epidermal growth factor receptor signaling. Sci Signal 6:ra31. doi: 10.1126/scisignal.2003705

Omiecinski CJ, Coslo DM, Chen T, et al (2011) Multi-species analyses of direct activators of the constitutive androstane receptor. Toxicol Sci 123:550-62. doi: 10.1093/toxsci/kfr191

Osabe M, Negishi M (2011) Active ERK1/2 protein interacts with the phosphorylated nuclear constitutive active/androstane receptor (CAR; NR1I3), repressing dephosphorylation and sequestering car in the cytoplasm. J Biol Chem 286:35763-35769. doi: 10.1074/jbc.M111.284596

Probert PME, Chung GW, Cockell SJ, et al (2014) Utility of B-13 progenitor-derived hepatocytes in hepatotoxicity and genotoxicity studies. Toxicol Sci 137:350-70. doi: 10.1093/toxsci/kft258

Probert PME, Chung GW, Cockell SJ, et al (2013) Utility of B-13 progenitor-derived hepatocytes in hepatotoxicity and genotoxicity studies. Toxicol Sci 137:350-370. doi: 10.1093/toxsci/kft258

Probert PME, Meyer SK, Alsaeedi F, et al (2015) An expandable donor-free supply of functional hepatocytes for toxicology. Toxicol Res 4:203-222. doi: 10.1039/C4TX00214H

Schmittgen TD, Livak KJ (2008) Analyzing real-time PCR data by the comparative C(T) method. Nat Protoc 3:1101-1108. doi: 10.1038/nprot.2008.73

Shen CN, Slack JM, Tosh D (2000) Molecular basis of transdifferentiation of pancreas to liver. Nat Cell Biol 2:879-87. doi: 10.1038/35046522

Shizu R, Shindo S, Yoshida T, Numazawa S (2012) MicroRNA-122 down-regulation is involved in phenobarbital-mediated activation of the constitutive androstane receptor. PLoS One 7:1-10. doi: 10.1371/journal.pone.0041291

Yamamoto Y, Moore R, Goldsworthy TL, et al (2004) The orphan nuclear receptor constitutive active/androstane receptor is essential for liver tumor promotion by phenobarbital in mice. Cancer Res 64:7197-200. doi: 10.1158/0008-5472.CAN-041459

Yang $\mathrm{H}$, Wang $\mathrm{H}$ (2014) Signaling control of the constitutive androstane receptor (CAR). Protein Cell 5:113-23. doi: 10.1007/s13238-013-0013-0

Yoshinari K, Kobayashi K, Moore R, et al (2003) Identification of the nuclear receptor CAR:HSP90 complex in mouse liver and recruitment of protein phosphatase $2 \mathrm{~A}$ in response to phenobarbital. FEBS Lett 548:17-20. doi: 10.1016/S0014-5793(03)00720- 
1

2

3

4

5

9

10

11

12

13

14

15

16

17

18

19

20

21

22

23

24

25

26

27

28

29

30

31

32

33

34

35

36

37

38

39

40

41

42

43

44

45

46

47

48

49

50

51

52

53

54

55

56

57

58

59

60

61

62

63

64

65 
Figures

Figure 1: Transdifferentiation of $\mathrm{B} 13 / \mathrm{H}$ cells.

Cyp2b activity was measured in B13 and transdifferentiated B13/H cells by PROD (A). Data were mean \pm SEM and representative of 3 independent cultures. Statistical significance was determined using Student's t test. ${ }^{* *} p<0.001$. A representative semi-q PCR of the samples shown in $(A)$ is presented $(B)$. A brightfield image of $B 13 / H$ cells is shown, and is representative of typical cell morphology $(C)$.

Figure 2: Phenobarbital induced cyp2b activity.

B13/H cells were treated with PB (2mM) and Cyp2b1 mRNA expression determined after $6 \mathrm{~h}$ (A) and Cyp2b enzyme activity determined at various time points up to 9 days (B) were assessed by $\mathrm{qRT}-\mathrm{PCR}$ or PROD, respectively. Data are mean \pm SEM and representative of 3 independent cultures. Statistical significance compared to control was determined using one way ANOVA with Dunnett's post test. ${ }^{*} p<0.05 ;{ }^{* *} p<0.01$.

Figure 3: Phenobarbital and Egf induced Erk and Akt activation.

Erk and Akt activity was measured in $\mathrm{B} 13 / \mathrm{H}$ cells pre-treated with $\mathrm{PB}(1 \mu \mathrm{M}$ or $5 \mathrm{mM})$ or erlotinib $(10 \mu \mathrm{M})$ for 30 minutes followed by BSA vehicle or Egf $(5 \mathrm{ng} / \mathrm{mL})$ for 60 minutes. Data were mean \pm SEM and representative of 3 independent cultures. A representative blot is shown (A) of Erk and Akt expression. The ratio of phospho-protein to total protein, after normalisation to the loading control Gapdh, from 3 separate immunoblots is expressed as fold change for Erk (B/C) and Akt (D). Statistical significance compared to control or Egf alone, and was determined using one way ANOVA with Dunnett's post test. ${ }^{* *} p<0.01$; ${ }^{* * *} \mathrm{p}<0.001$.

Figure 4: Phenobarbital and Hgf induced Erk activation.

Erk activity was measured in B13/H cells pre-treated with PB $(1 \mu \mathrm{M}$ or $5 \mathrm{mM})$ for 30 minutes followed by BSA vehicle or $\mathrm{Hgf}(20 \mathrm{ng} / \mathrm{mL})$ for 60 minutes. Data were mean \pm SEM and representative of 3 independent cultures. The ratio of phospho-protein to total protein, after normalisation to the loading control Gapdh, from 3 separate immunoblots is expressed as 
fold change for Erk. Statistical tests compared to control or Hgf alone, and was determined using one way ANOVA with Dunnett's post test.

Figure 5: Effect of PB treatment on miR expression

$\mathrm{B} 13 / \mathrm{H}$ cells were treated with $\mathrm{PB}(100 \mu \mathrm{M}$ or $2 \mathrm{mM})$ for up to 9 days and the relative expression of miR-96 (A) and miR-182 (B) was determined by qRT-PCR. Data were mean \pm SEM and representative of 3 independent cultures. Statistical significance compared to control was determined using one way ANOVA with Dunnett's post test. ${ }^{* *} p<0.01$.

Figure 6: Effect of clotrimazole on cyp2b activity and miR 96 expression.

$\mathrm{B} 13 / \mathrm{H}$ cells were treated with clotrimazole $(10 \mu \mathrm{M})$ for up to 9 days and Cyp2b1 enzyme activity (A) and miR-96 expression (B) were determined. Data were mean \pm SEM and representative of 3 independent cultures. Statistical significance compared to control was determined using one way ANOVA with Dunnett's post test. ${ }^{*} p<0.05 ;{ }^{* *} p<0.01$.

Figure 7: Effect of TCPOBOP on cyp2b activity and miR96/182 expression

B13/H cells were treated with TCPOBOP $(1.5 \mu \mathrm{M})$ for up to 9 days and Cyp2b1 enzyme activity $(A)$ and miR-96 (B) and miR-182 expression (C) were determined. Data were mean \pm SEM and representative of 3 independent cultures. Statistical significance compared to control was determined using one way ANOVA with Dunnett's post test.

Figure 8: Effect of phenobarbital treatment of $\mathrm{B} 13 / \mathrm{H}$ cells on miR122 expression.

MiR-122 expression was measured in 24 hour PB treated (100 $\mathrm{MM}-4 \mathrm{mM}) \mathrm{B} 13 / \mathrm{H}$ cells. Data were mean \pm SEM and representative of 3 independent cultures. Statistical significance compared to control was determined using one way ANOVA with Dunnett's post test. ${ }^{* * \star *} p<0.0001$. 
Click here to download high resolution image

Figure 1

A B-13/H cell Cyp2b activity compared to B13

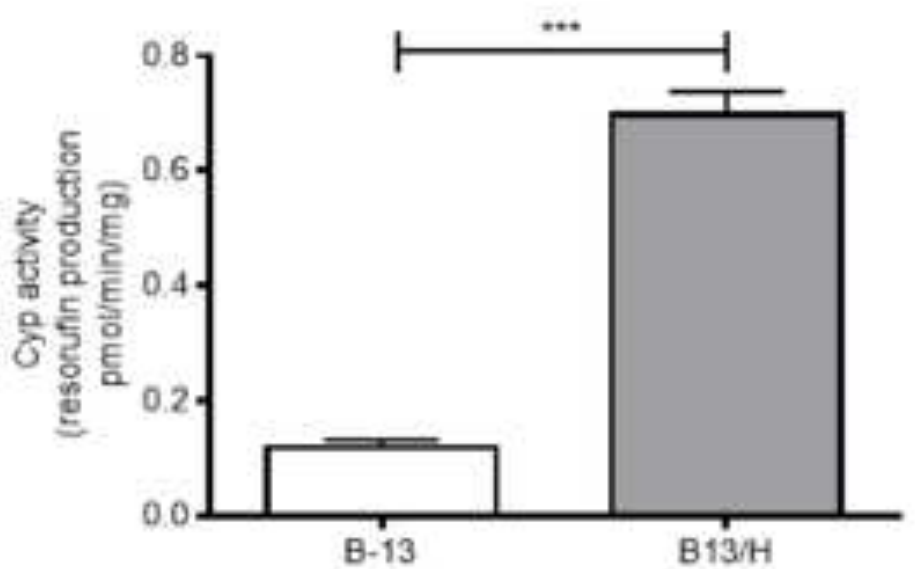

B

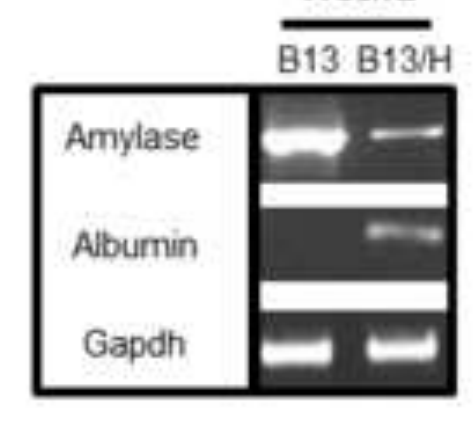

c

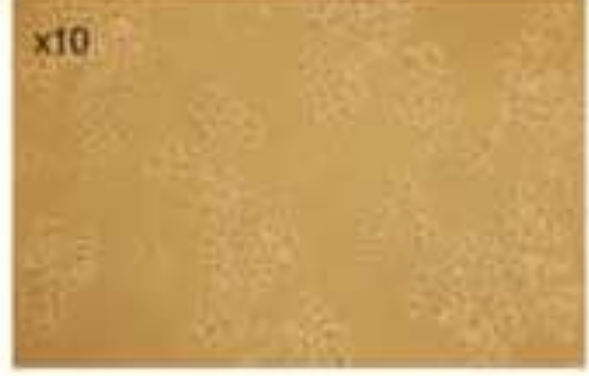


Figure 2

A

Cyp2b1 mRNA expression in B13/H with $6 \mathrm{hr} P B$

B
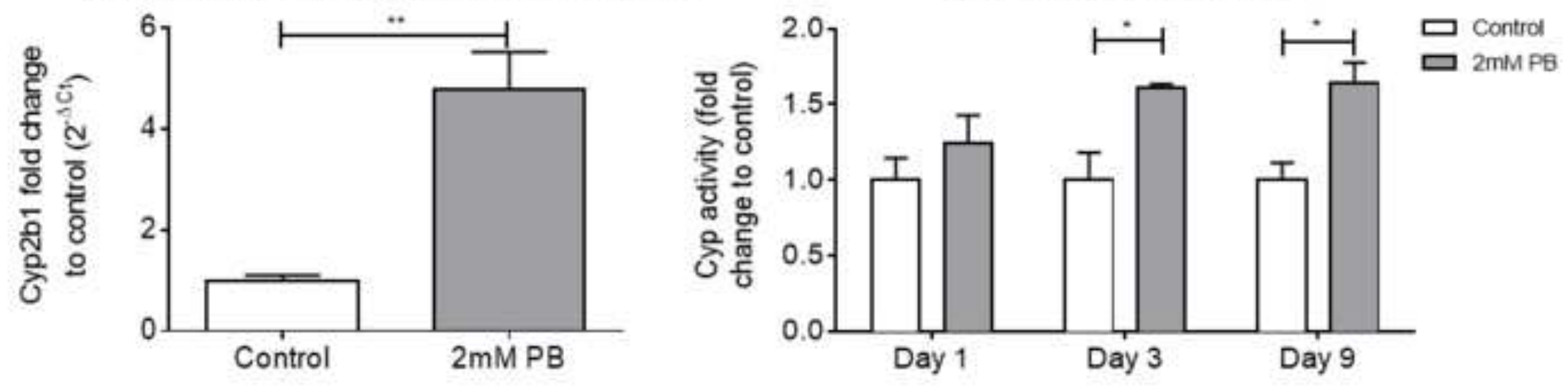
Figure 3

A

\begin{tabular}{|c|c|c|c|c|c|c|c|c|}
\hline $\begin{array}{l}-30 \\
\text { min }\end{array}$ & Veh & $\begin{array}{l}\text { 10, } \\
\text { EN }\end{array}$ & $\begin{array}{l}10,0 \\
\text { EN }\end{array}$ & Veh & $\begin{array}{l}1, \mu \\
\theta\end{array}$ & $\begin{array}{l}5 \mathrm{pen} \\
\mathrm{PQ}\end{array}$ & $\begin{array}{l}\text { Tyen } \\
\mathrm{PB}\end{array}$ & $\begin{array}{l}\mathrm{Sen} \\
\mathrm{PB}\end{array}$ \\
\hline${ }_{\min }^{0}$ & Veh & Veh & $\begin{array}{l}50 \mathrm{~d} \\
\mathrm{~mL} \\
\mathrm{Egth}^{2}\end{array}$ & $\begin{array}{l}5 n q \\
m L \\
E_{g t}\end{array}$ & $\begin{array}{l}\text { Sap } \\
\text { ed } \\
\text { Egt }\end{array}$ & 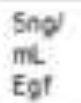 & Veh & Veh \\
\hline
\end{tabular}

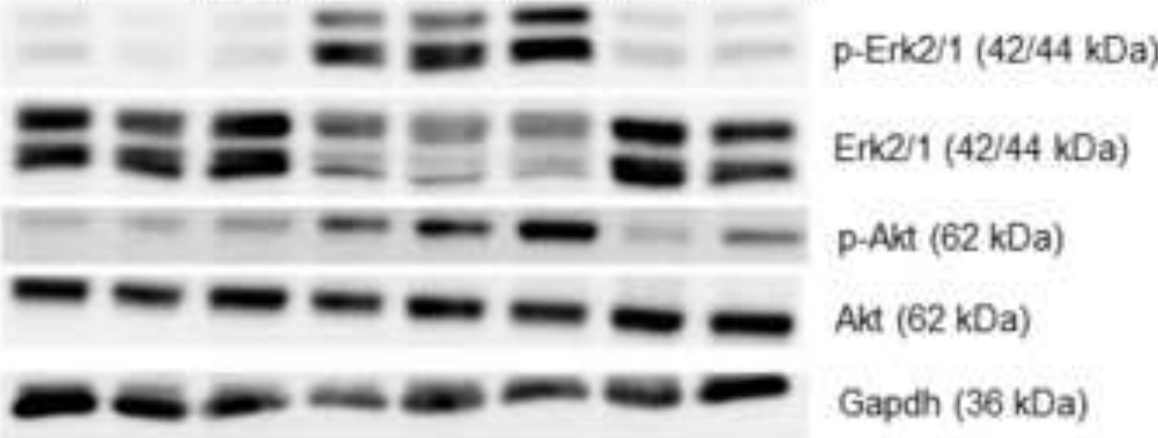

Erk activation in B13/ $\mathrm{H}$ cells after $72 \mathrm{hrs}$ C $5 \%$ stripped media and $30 \mathrm{~min}$

PB pre-treatment prior to 60 mins Egf

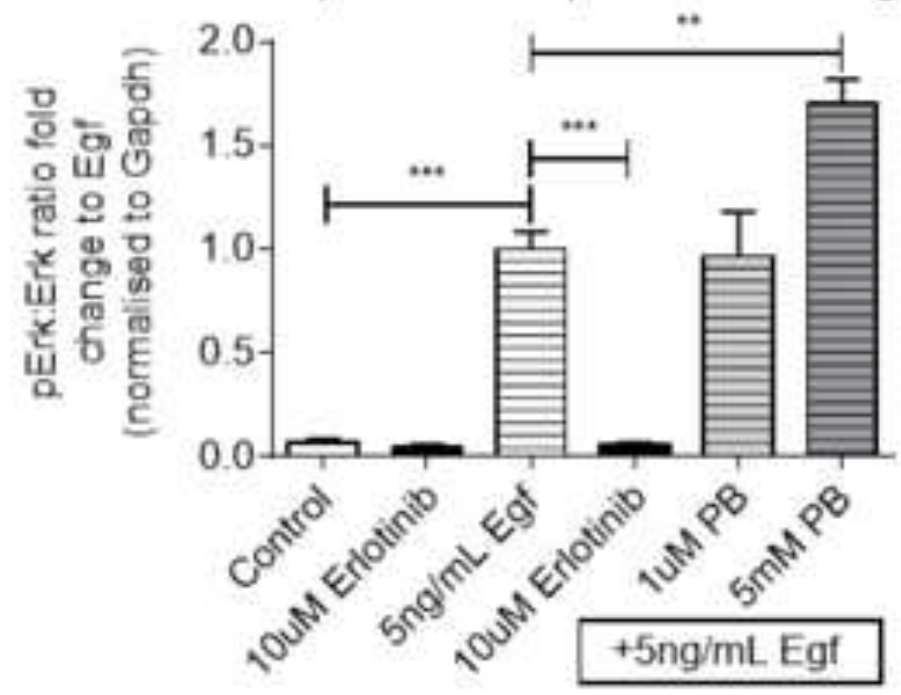

Erk activation in $\mathrm{B} 13 / \mathrm{H}$ cells after $72 \mathrm{hrs}$ $5 \%$ stripped media and $30 \mathrm{~min}$ PB pre-treatment prior to 60 mins Egf

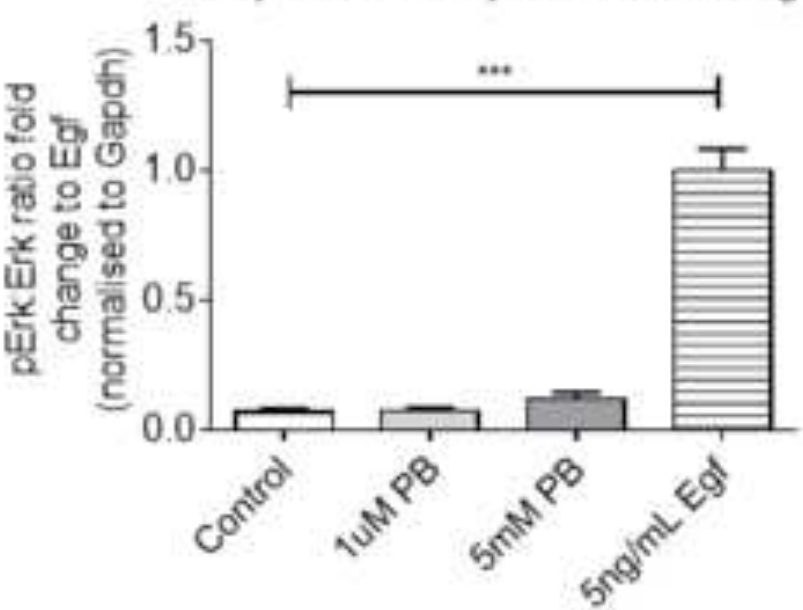

Akt activation in B13/H cells after $72 \mathrm{hrs}$ $5 \%$ stripped media and $30 \mathrm{~min}$ PB pre-treatment prior to 60 mins Egf

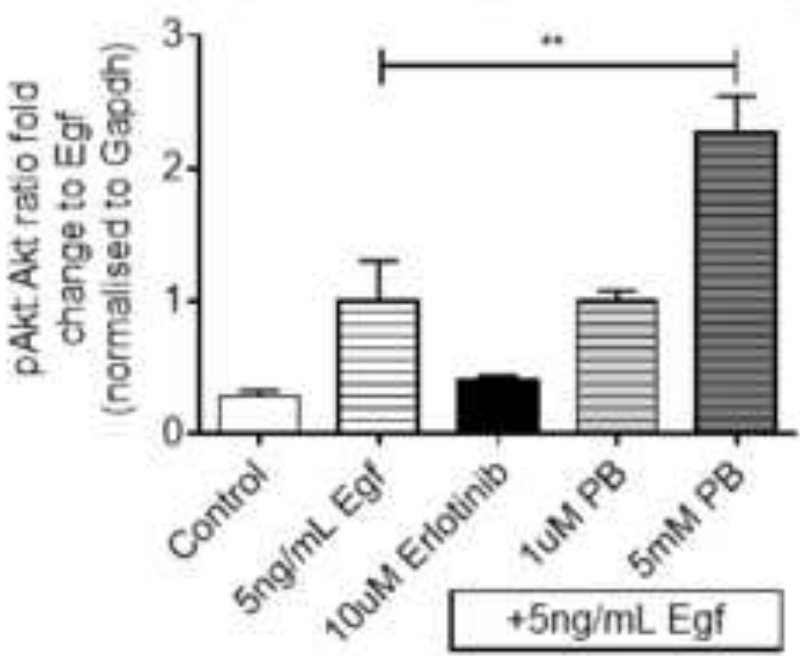


Figure 4

Erk activation in $\mathrm{B} 13 / \mathrm{H}$ cells after $72 \mathrm{hrs}$ $5 \%$ stripped media and $30 \mathrm{~min}$

$\mathrm{PB}$ pre-treatment prior to 60 mins $\mathrm{Hgf}$

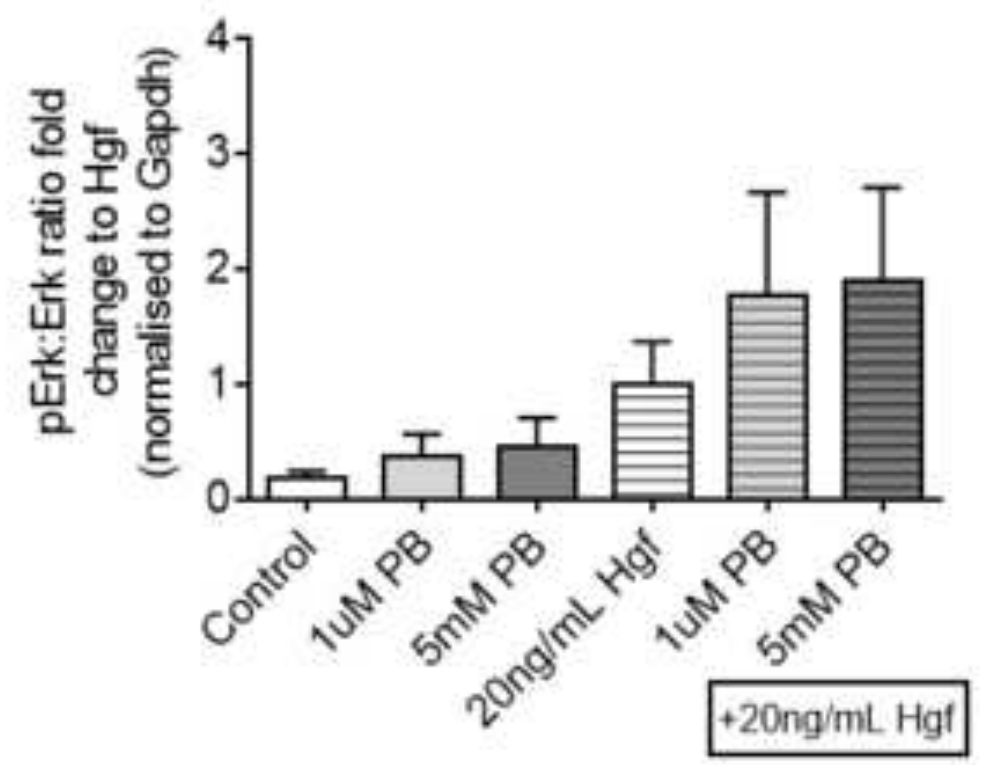


A miR-96 expression in B13/H cells

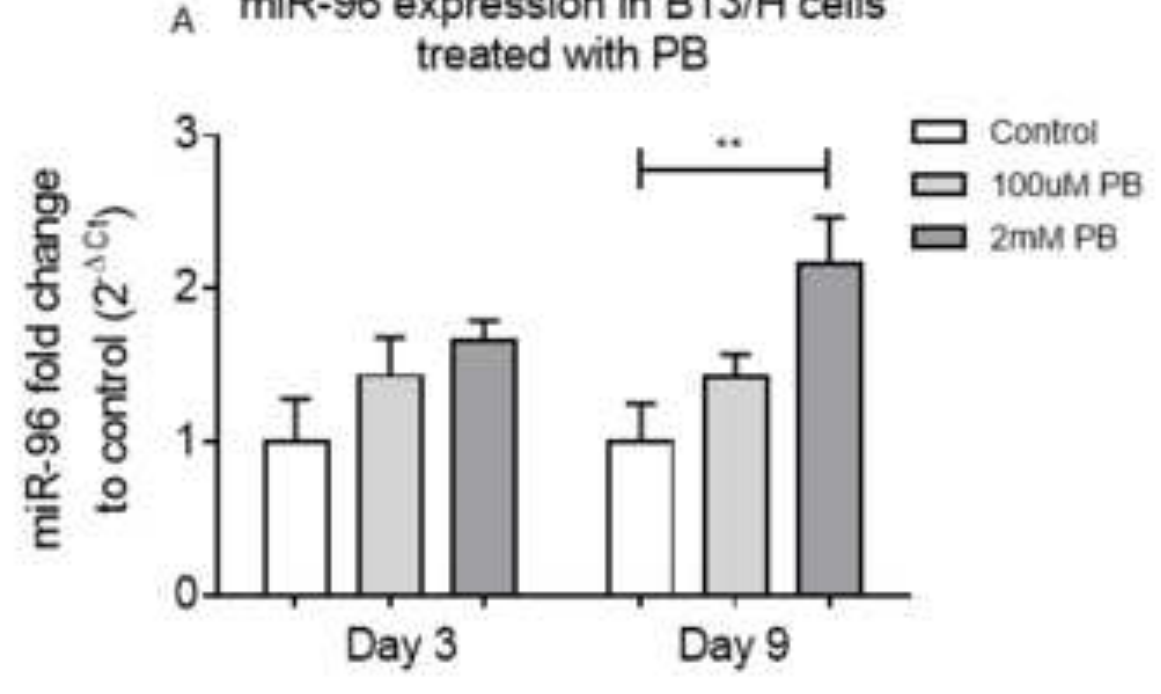

\section{B miR-182 expression in B13/H cells}

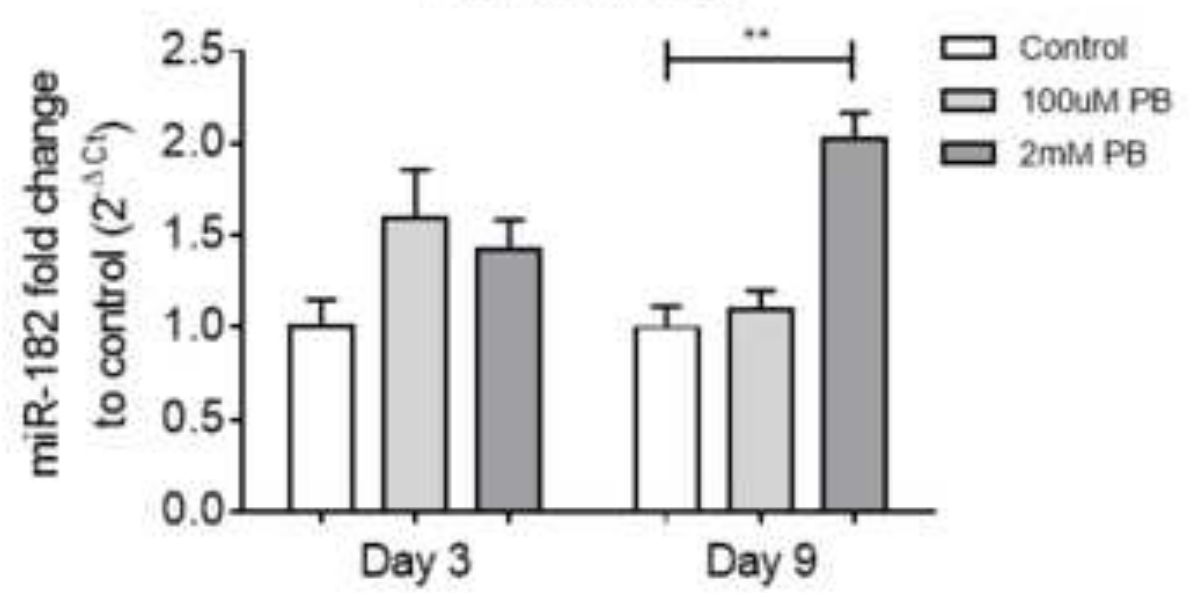


Figure 6

A

Cyp2b activity in $\mathrm{B} 13 / \mathrm{H}$ cells

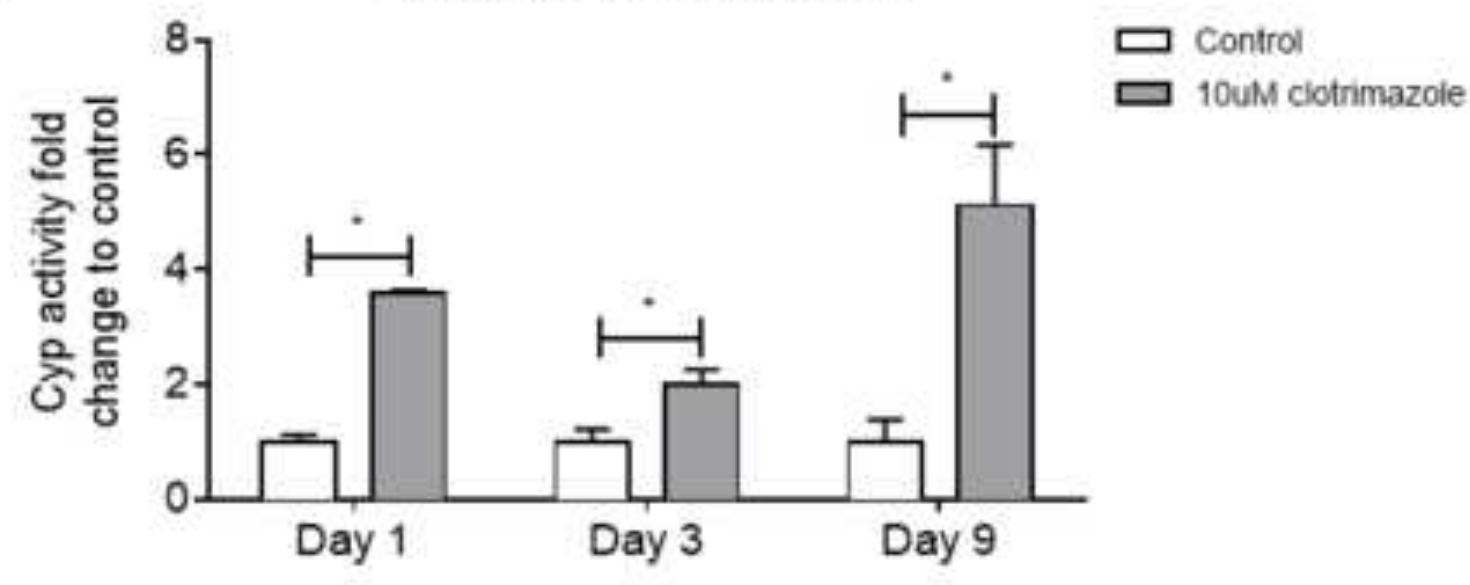

B

miR-96 expression in B13/H cells treated with clotrimazole

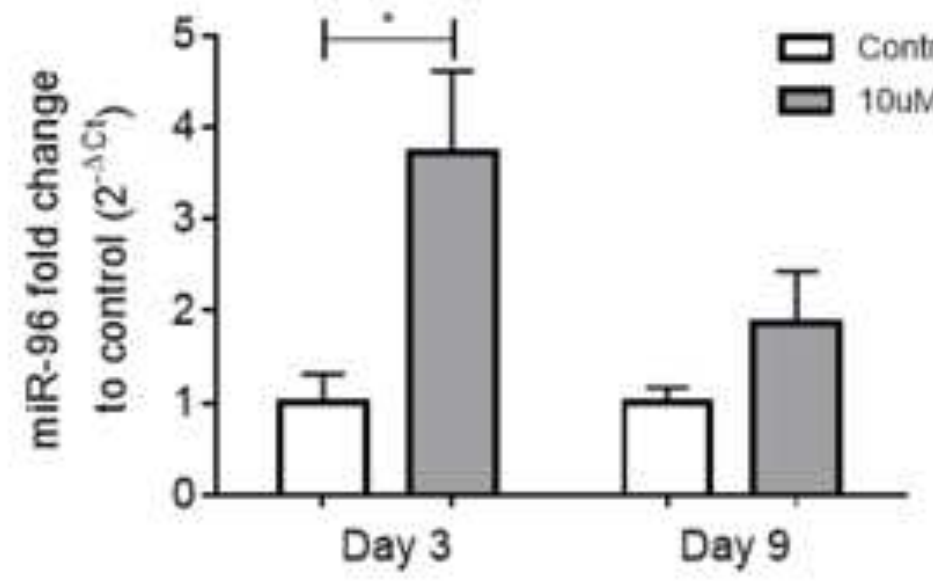


Figure 7
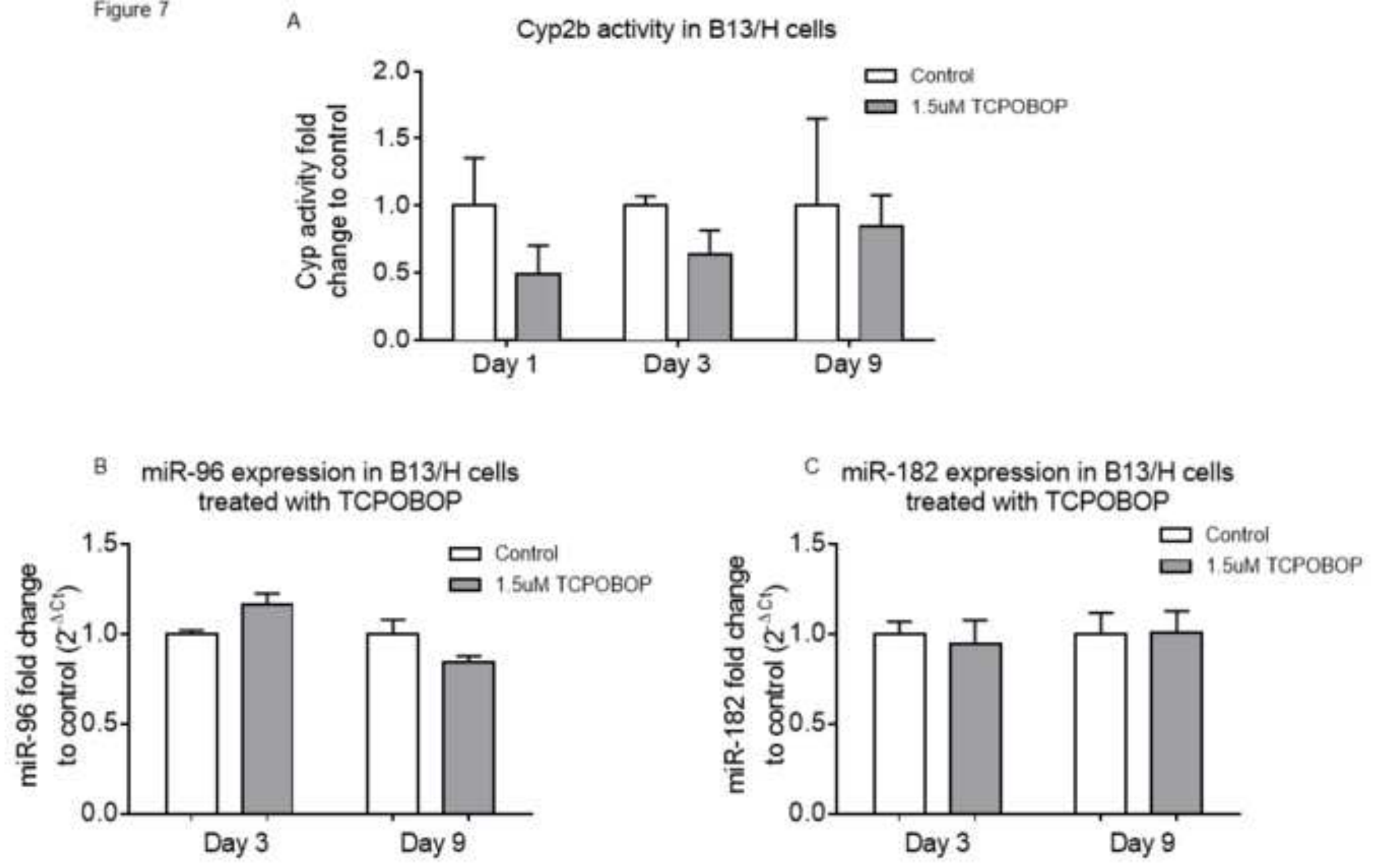
Click here to download high resolution image

Figure 8

miR-122 expression in $\mathrm{B} 13 / \mathrm{H}$ cells treated with $\mathrm{PB}$ for 24 hours

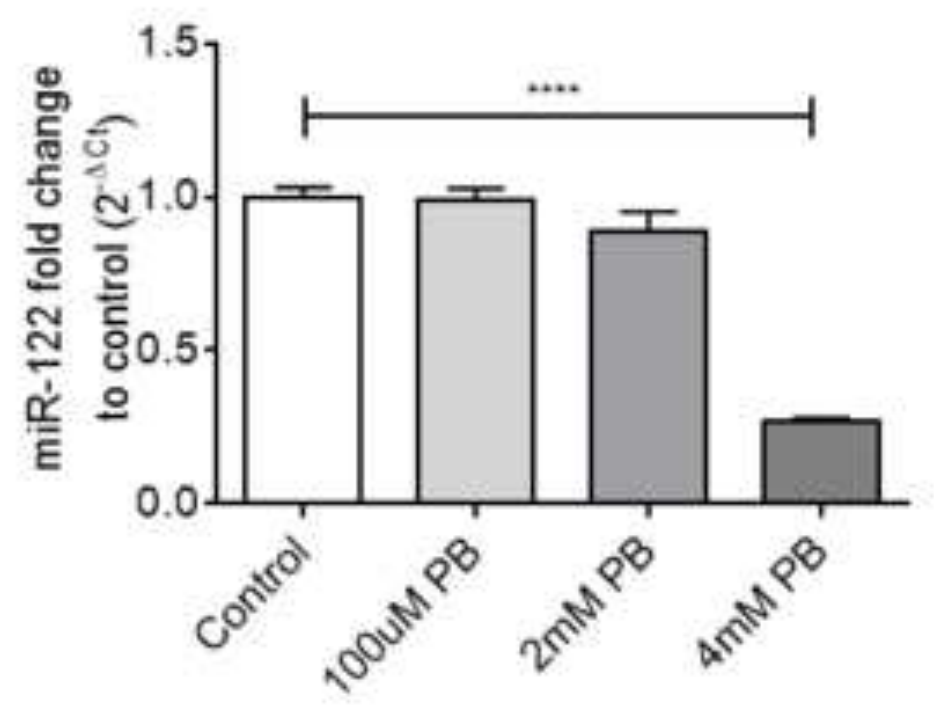

